\title{
Lesiones esofágicas por reflujo gastroesofágico
}

\section{Esophageal lesions due to gastroesophageal reflux}

\author{
Henry Alberto Royero-Gutiérrez • Ocaña (Colombia)
}

DOI: https://doi.org/10.36104/amc.2019.1330

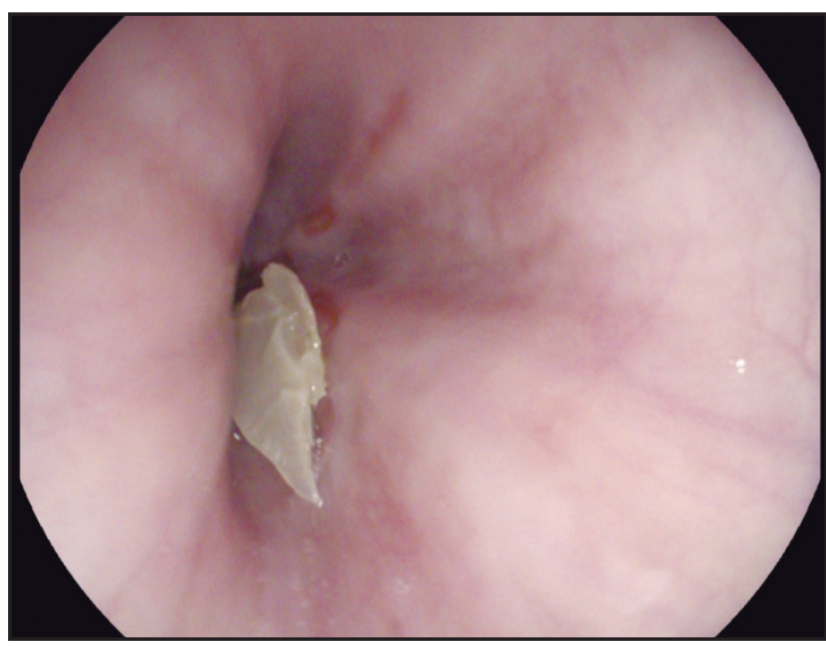

Figura 1. Cuerpo extraño esofágico constituido por material vegetal.

Masculino de 50 años, consulta por pirosis de cinco años de evolución, durante el último año disfagia esofágica. La esofagoscopia observó cuerpo extraño constituido por material vegetal, luego de retirarlo, se encontró estrechamiento $(<12.5 \mathrm{~mm})$ que impide el paso del endoscopio; proximal a ésta, rupturas de mucosa esofágica que abarcan menos de $75 \%$ de su circunferencia, con una longitud máxima de $1.5 \mathrm{~cm}$. No se tomaron biopsias por friabilidad de la mucosa. (Figuras 1,2). Se diagnosticó: estenosis esofágica por reflujo gastroesofágico (RGE), sospecha de metaplasia esofágica (esófago de Barrett) y esofagitis grado C. El modelo actual en el diagnóstico del RGE gira en torno a la identificación de síntomas

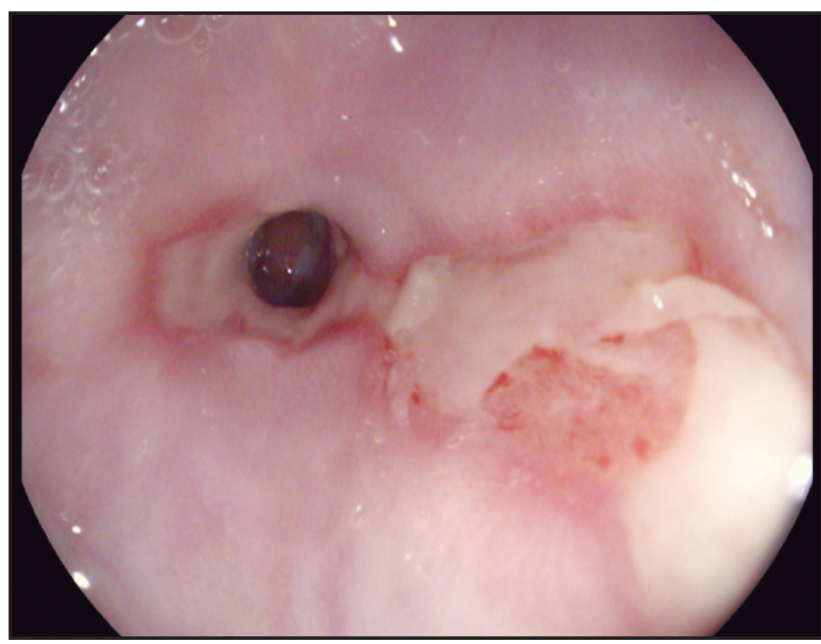

Figura 2. Estenosis esofágica, Esofagitis grado $C$ y sospecha endoscópica de metaplasia esofágica.

esofágicos y extra esofágicos además del daño de la mucosa (esofagitis, esófago de Barrett, estenosis y adenocarcinoma) $(1,2)$. El caso ilustra tres complicaciones esofágicas por RGE. Se indicó dilatación esofágica, tratamiento con Omeprazol y seguimiento para descartar histológicamente esófago de Barrett.

\section{Referencias}

1. Vakil N, van Zanten SV, Kahrilas P. Dent J, Jones R. The Montreal definition and classification of gastroesophageal reflux disease: a global evidence-based Consensus. Am J gastroneterol 2006; 101: 1900-20

2. Gyawali C, Kahrilas P, Savarino E, Zerbib F, Mion F, Somut A, et al. Modern diagnosis of GERD: the Lyon Consensus. Gut online first, published on February 9,2018 as 10.1136 / gutjnl 2017-314722

Dr. Henry Alberto Royero-Guitiérrez: Internista-Gastroenterólogo. Ocaña, Norte de Santander. Ocaña (Colombia).

Correspondencia: Henry Alberto Royero Gutiérrez. Ocaña (Norte de Santander).

E-mail: royerogastro@hotmail.com

Recibido: 7/VII/2019 Aceptado: 20/XI/2019 